\title{
Impact of depression and anxiety on burden and management of episodic and chronic headaches - a cross-sectional multicentre study in eight Austrian headache centres
}

Karin Zebenholzer ${ }^{1 *}$, Anita Lechner ${ }^{2}$, Gregor Broessner ${ }^{3}$, Christian Lampl ${ }^{4}$, Gernot Luthringshausen ${ }^{5}$, Albert Wuschitz ${ }^{6}$, Sonja-Maria Obmann ${ }^{7}$, Klaus Berek $^{8}$ and Christian Wöber ${ }^{1}$

\begin{abstract}
Background: Recurrent and especially chronic headaches are associated with psychiatric comorbidities such as depression and anxiety. Only few studies examined the impact of depression and anxiety on episodic (EH) and chronic headache $(\mathrm{CH})$, and data for Austria are missing at all. Therefore, the aim of the present study was to assess the impact of depression and anxiety on burden and management of $\mathrm{EH}$ and $\mathrm{CH}$ in patients from eight Austrian headache centres.

Methods: We included 392 patients (84.1\% female, mean age $40.4 \pm 14.0$ years) who completed the Eurolight questionnaire. The treating physician recorded details about ever-before prophylactic medications. We used Hospital Anxiety and Depression Scale to assess depression and anxiety and compared patients with anxiety and/or depression to those without.

Results: Depression and anxiety were more common in $\mathrm{CH}$ than in $\mathrm{EH}(64 \%$ vs. $41 \%, p<0.0001$ ). Presence compared to absence of depression and anxiety increased the prevalence of poor or very poor quality of life from $0.7 \%$ to $13.1 \%$ in EH and from $3.6 \%$ to $40.3 \%$ in $\mathrm{CH}(p=0.001 ; p<0.0001)$. Depression and anxiety had a statistically significant impact on employment status and on variables related to the burden of headache such as reduced earnings, being less successful in career, or feeling less understood. Neither in $\mathrm{EH}$ nor in $\mathrm{CH}$ health care use and the ever-before use of prophylactic medication was correlated with anxiety and/or depression.
\end{abstract}

Conclusion: Depression and anxiety have a significant impact on quality of life and increase the burden in patients with $\mathrm{EH}$ and $\mathrm{CH}$. Improved multidimensional treatment approaches are necessary to decrease disability on the personal, social and occupational level in these patients.

Keywords: Episodic headache, Chronic headache, Migraine, Tension-type headache, Medication overuse headache, Depression, Anxiety, Psychiatric comorbidity, Burden, Quality of life

\footnotetext{
* Correspondence: karin.zebenholzer@meduniwien.ac.at

'Department of Neurology, Medical University of Vienna, Währinger Gürtel

18-20, 1090 Vienna, Austria

Full list of author information is available at the end of the article
} 


\section{Background}

Headache is a frequent disorder with one-year prevalence rates of $10-18.6 \%$ for migraine and $31-90 \%$ for tension-type headache, and it is often interfering with everyday life [1-3]. Headache, especially migraine, is associated with comorbidities such as anxiety disorders and depression, ranging from $18-58 \%$ for anxiety disorders and $17-47 \%$ for depression [4-7]. In addition, headache patients, especially those with migraine or chronic daily headache, showed reduced quality of life $[8,9]$, and the burden caused by any headache is high with regard to lost workdays, lost days with household activities, lost family, social and leisure activities [10, 11]. Recent studies showed that significantly more patients with chronic migraine suffer from psychiatric comorbidities than patients with episodic migraine (31 - $58 \%$ vs. $17-30 \%)$, and that patients with chronic migraine had lower household incomes and were less likely to be employed fulltime [4, 5, 9].

To assess the prevalence of episodic headache $(\mathrm{EH})$ and chronic headache $(\mathrm{CH})$, management and burden of $\mathrm{EH}$ and $\mathrm{CH}$ in patients in Austrian headache centres, we performed a prospective, multicentre study in eight headache centres published in 2015 [11]. Within this study we collected also data on depression and anxiety. Depression and anxiety may cause additional burden in headache sufferers with respect to productivity loss, quality of life, health care utilization, and emotional burden. So far only few studies addressed the impact of psychiatric comorbidities in patients with migraine and headache in general [12-14]. None of these studies compared $\mathrm{EH}$ to $\mathrm{CH}$ and data for Austria are missing at all.

Therefore the aim of the present study was to assess the impact of depression and anxiety on burden and management of patients with $\mathrm{EH}$ and $\mathrm{CH}$ from eight Austrian headache centres.

\section{Methods}

In April 2011 and September 2011 all consecutive patients attending one of eight Austrian headache centres for a first-time or follow-up visit were invited to participate in the study. Inclusion criteria were age $\geq 18$ years, primary headache, medication overuse headache, and fluent German. Exclusion criteria were secondary headaches except medication overuse headache, fibromyalgia, other chronic pain disorders, and lacking knowledge of German. Four centres were at departments of medical universities, three centres were at large hospitals, and one centre was a large neurological office in Vienna. The study was approved by the ethics committee of the Medical Universities of Vienna, Graz, Innsbruck and Salzburg and local ethics committees of the other participating departments.
After giving written informed consent the patients completed the Eurolight questionnaire once. The Eurolight questionnaire was developed to gather data on the personal, social and economic impact of migraine, TTH and $\mathrm{MOH}$ in 15 countries in the European Union (EU) $[10,15]$. It is a 103-item self-reporting questionnaire, validated in five languages, with good construct validity, good test-retest reliability and good internal consistency [15]. The questionnaire covers biographic data, headache symptoms, use of acute and prophylactic medications during the previous month, former examinations due to headache, quality of life as well as symptoms of anxiety and depression. The Eurolight questionnaire differentiates $\mathrm{EH}$, i.e. headache on $<15$ days/month, and $\mathrm{CH}$, i.e. headache on $\geq 15$ days/month, and it is validated for diagnosing migraine, probable migraine, tension -type headache (TTH), probable tension-type headache (pTTH) and probable medication overuse headache (pMOH) according to ICHD-2 $[15,16]$. Other headaches than mentioned above are classified as "other headache". It does not allow diagnosing the underlying headache in patients with $\mathrm{CH}$ and $\mathrm{pMOH}$. Therefore we diagnosed these patients based on their questionnaire entries concerning their most bothersome headache.

The questionnaire also includes the HALT index (Headache-attributed lost time index) for assessing days lost completely or partially because of headache [10, 17], the WHOQoL-8 (WHO quality of life assessment) [18], and the Hospital Anxiety and Depression scale (HADS) [19]. The HALT index captures in five questions the days lost completely or partially because of headache in the preceding three months and covers professional work, household activities or chores, and family, social or leisure activities. To estimate the burden of headache, and because data were not normally distributed, we summarized these lost days during the previous three months and categorized the impact of headache into 0-5 days lost, 6-10 days lost, 11-20 days lost, and $>20$ days lost. We assessed the patients' quality of life by using the first question of the WHOQoL-8 that asks the patients to rate their general quality of life on a five-point scale (poor, very poor, neither good nor poor, good, very good) [18], and we used the HADS for assessing anxiety and depression [19]. The HADS has seven items each for assessing anxiety and depression. Anxiety or depression was rated as present if the HADS-A score or the HADS$\mathrm{D}$ score was $\geq 8$ [19]. If one of the subscales indicated depression or anxiety and the other subscale was missing, we rated depression and/or anxiety as present. If one subscale was not indicative of anxiety or depression and the other subscale was missing, we rated depression and anxiety data as missing.

In addition to the questionnaire completed by the patients, the treating neurologist filled in a questionnaire 
covering the clinical headache diagnosis and ever-before intake of five classes of standard prophylactic medication (betablocker, flunarizine, valproate, topiramate, amitriptyline). For each of these drug classes the treating neurologist had to assess, if it was contraindicated and if it was ever taken by the patient. If it had ever been taken, four additional questions had to be answered: (1) Was the treatment stopped because of intolerable adverse effects, (2) was the dose sufficient according to national and international guidelines [20,21], (3) was the drug taken for at least three months, and (4) was headache frequency decreased by at least $50 \%$ while taking this prophylactic drug?

For the initial study we screened 598 consecutive patients, 121 patients denied participation or had to be excluded, mainly because of lacking fluency in German, 36 questionnaires had to be excluded for incomplete data. Thus the analysis was based on 441 patients [11], of these $56.3 \%$ had $\mathrm{EH}, 38.3 \%$ had $\mathrm{CH}$, and patients with $\mathrm{CH}$ had a significantly lower quality of life and significantly more often depression or anxiety [11]. For the present study we included all patients with available data on headache frequency in the Eurolight questionnaire and on prophylactic medication in the questionnaire completed by the treating neurologist.

\section{Statistics}

We applied the standard computerized algorithm to analyse data derived from the Eurolight questionnaire [22]. We compared patients with $\mathrm{EH}$ to patients with $\mathrm{CH}$, and for assessing the impact of depression and anxiety we compared patients with depression and/or anxiety and without depression and/or anxiety both in patients with $\mathrm{EH}$ and $\mathrm{CH}$. We used numbers and percentages for descriptive statistics and $\mathrm{Chi}^{2}$-tests for comparing patients with and without depression and/ or anxiety differentiating $\mathrm{EH}$ and $\mathrm{CH}$. For comparisons of continuous variables we used t-tests. We calculated odds ratios to assess the risk of burden for presence versus absence of depression and/or anxiety in the entire group of patients and in those with $\mathrm{EH}$ and $\mathrm{CH}$. For assessing the impact of depression and anxiety on the use of five classes of standard prophylactic medications we dichotomized ever-before use, contraindications, adverse effects, use for at least three months, intake of an adequate dose, and decrease in headache frequency by at least $50 \%$ and compared presence in none versus presence in one or more of the drugs. Two-sided $p$-values $<0.05$ were considered as statistically significant. As this was an exploratory study, we did not correct for multiple testing. Standardized Eurolight analyses were done with SAS 9.2, all other statistical analyses were performed using SPSS 20.0.

\section{Results}

We included 392 patients with available data on headache frequency in the Eurolight questionnaire and with the completed additional questionnaire filled-in by the treating neurologist. Table 1 shows gender, depression and/or anxiety and headache diagnoses in $\mathrm{EH}$ compared to $\mathrm{CH}$. Of 392 patients 301 (79.1\%) were female, 82 $(20.9 \%)$ male. The proportion of males was significantly higher among patients with $\mathrm{CH}$ (Table 1). Twohundred-thirty-two patients (59.2 \%) had EH, and 160 (40.8\%) patients had $\mathrm{CH}$, among the latter 65 (40.6\%) had $\mathrm{pMOH}$. Patients with $\mathrm{EH}$ and $\mathrm{CH}$ did not differ in age $(40.3 \pm 13.3$ vs. $40.4 \pm 14.9$ years, $p=0.9)$. In $\mathrm{EH} 92$ patients (40.2\%) and in $\mathrm{CH} 97$ patients $(63.8 \%)$ had depression and anxiety or at least one of these psychiatric disorders $(p<0.0001)$. The prevalence of depression alone and anxiety alone was significantly higher in patients with $\mathrm{CH}$ (depression $43.6 \%$, anxiety $53.9 \%$ ) than in patients with $\mathrm{EH}$ (depression $22.8 \%$, anxiety $34.1 \% p$ $<0.0001$ (Table 1). Regarding headache diagnoses 199 (85.8\%) patients with $\mathrm{EH}$ had migraine; among the patients with $\mathrm{CH} 69$ (43.1 \%) had migraine, and 65 (40.6 \%) had pMOH (Table 1).

Table 1 Gender, depression, anxiety and headache diagnoses in patients with $\mathrm{EH}$ and $\mathrm{CH}$

\begin{tabular}{|c|c|c|c|c|c|c|}
\hline & \multirow{2}{*}{\multicolumn{2}{|c|}{$\begin{array}{l}\text { EH }(n=232) \\
\text { Patients }\end{array}$}} & \multirow{2}{*}{\multicolumn{2}{|c|}{$\frac{\mathrm{CH}(n=160)}{\text { Patients }}$}} & \multirow{3}{*}{$\mathrm{Chi}^{2}$} & \multirow{3}{*}{$p$} \\
\hline & & & & & & \\
\hline & $n$ & $\%$ & $n$ & $\%$ & & \\
\hline \multicolumn{7}{|l|}{ Sex } \\
\hline Female & 198 & 84.1 & 112 & 71.9 & 13.5 & $<0.0001$ \\
\hline Male & 34 & 15.9 & 48 & 28.1 & & \\
\hline \multicolumn{7}{|l|}{ Anxiety } \\
\hline \multicolumn{7}{|l|}{ Missing data: 9} \\
\hline Yes & 78 & 34.1 & 83 & 53.9 & 14.9 & $<0.0001$ \\
\hline No & 151 & 65.9 & 71 & 46.1 & & \\
\hline \multicolumn{7}{|l|}{ Depression } \\
\hline \multicolumn{7}{|l|}{ Missing data: 19} \\
\hline Yes & 51 & 22.8 & 65 & 43.6 & 18.2 & $<0.0001$ \\
\hline No & 173 & 77.2 & 84 & 56.4 & & \\
\hline \multicolumn{7}{|c|}{ Anxiety and/or depression } \\
\hline \multicolumn{7}{|l|}{ Missing data: 14} \\
\hline Yes & 92 & 40.7 & 97 & 63.8 & 19.4 & $<0.0001$ \\
\hline No & 134 & 59.3 & 55 & 36.2 & & \\
\hline \multicolumn{7}{|l|}{ Headache diagnosis } \\
\hline Migraine & 199 & 85.8 & 69 & 43.1 & 79.7 & $<0.0001$ \\
\hline Tension-type HA & 27 & 11.6 & 22 & 13.8 & & ns \\
\hline Other HA & 6 & 2.6 & 4 & 2.5 & & ns \\
\hline $\mathrm{pMOH}$ & - & - & 65 & 40.6 & & na \\
\hline
\end{tabular}

$\mathrm{EH}$ episodic headache, $\mathrm{CH}$ chronic headache, $\mathrm{pMOH}$ probable medication overuse headache, $n s$ not significant; $n a$ not applicable 
Looking at $\mathrm{EH}$ and $\mathrm{CH}$ patients separately, the mean age did not differ between with and without depression and/or anxiety: EH with depression and/or anxiety 39.7 \pm 12.3 years, EH without depression and/or anxiety 41.2 \pm 14.6 years; $\mathrm{CH}$ with depression and/or anxiety $38.8 \pm$ 14.3 years, $\mathrm{CH}$ without depression and/or anxiety $41.6 \pm$ 15.6 years. Also gender did not differ significantly between patients with and without depression and/or anxiety (Table 2). Table 2 shows the impact of anxiety and depression on patients with $\mathrm{EH}$ and $\mathrm{CH}$. Headache diagnoses did not depend on presence or absence of anxiety and/or depression. Both in $\mathrm{EH}$ and $\mathrm{CH}$ significantly more patients with depression and/or anxiety had a worse quality of life (poor or very poor quality of life in EH 12 patients (13.1\%), in $\mathrm{CH} 30$ patients (31.3\%), $p<0.0001)$, higher unemployment rates (in EH 23 patients (26.4 \%), in $\mathrm{CH} 42$ patients (45.2\%), $p<0.0001$ ), and missed the feeling of being understood by colleagues/employers (in EH 27 patients (48.2 \%), in $\mathrm{CH} 27$ patients (51.9\%), $p=0.039$ ). In $\mathrm{EH}$ but not in $\mathrm{CH}$ significantly more patients with depression and/or anxiety reported that they had been less successful in their careers, had reduced earnings due to headaches, and that they felt less understood by their families (Table 2). In $\mathrm{CH}$ but not in EH significantly more patients with depression and/or anxiety avoided telling other people about their headaches, and the number of patients who lost more than ten days because of headache during the previous three months was higher in those with depression and/or anxiety; but the latter did not reach statistical significance. In both groups the interference with education and the feeling of being in control of the headache was independent of depression and/or anxiety (Table 2).

These findings appeared even more pronounced using risk calculations (Table 3). Analysing all patients the presence of depression and/or anxiety increased the risk of $\mathrm{CH}$ (OR 2.5) and pMOH (OR 2.48), it markedly decreased quality of life and it increased burden. The risk of poor or very poor quality of life was almost 18 -fold higher in patients with depression and/or anxiety compared to those without. The burden was higher for seven of the other nine variables with odds ratios ranging from 1.75 to 4.8 (Table 3). Assessing the impact of depression and/or anxiety separately for $\mathrm{EH}$ and $\mathrm{CH}$ the odds ratio for poor or very poor quality of life was 19.95 and 12.05 , respectively, and the burden was increased in $\mathrm{EH}$ and $\mathrm{CH}$ in six and four of the other nine variables showing odds ratios of 2.2. to 4.5 and 2.15 to 6.3 , respectively (Table 3 ).

Patients with $\mathrm{CH}$ consulted general practitioners significantly more often than patients with EH (61/39.1\% vs. $65 / 29.1 \% ; p=0.043)$, consultations of other health care professionals did not differ between patients with $\mathrm{EH}$ and $\mathrm{CH}$. Depression and/or anxiety had no impact on headache-related health care consultations (headache specialist, general practitioner, hospital emergency room, nurse, physical therapist) and examinations (magnetic resonance imaging, computer tomography, X-ray, eye test, blood tests) during the previous 12 months in $\mathrm{EH}$ and $\mathrm{CH}$. The impact of depression and/or anxiety on the use of five classes of standard prophylactic medications was minimal. In $\mathrm{EH}$ but not in $\mathrm{CH}$ patients with depression and/or anxiety had significantly more contraindications than those without (EH without depression and/or anxiety 29 patients (23.2\%), EH with depression and/or anxiety 31 (36.5\%), $p=0.037 ; \mathrm{CH}$ without depression and/or anxiety 12 patients (22.6\%), $\mathrm{CH}$ with depression and/or anxiety 18 (20.9\%), $p>0.05$. Neither in EH nor in $\mathrm{CH}$ ever-before use of prophylactics, adverse effects, use for at least three months, intake of an adequate dose and decrease of headache frequency by at least $50 \%$ was statistically associated with depression and/or anxiety (Table 4).

\section{Discussion}

This post-hoc analysis of a prospective, cross-sectional multicentre study in eight Austrian headache centres showed a significantly higher prevalence of anxiety and/ or depression in $\mathrm{CH}$ (64 \%) than EH (41\%). Depression and anxiety had a marked impact on quality of life and increased the burden in patients with $\mathrm{EH}$ and $\mathrm{CH}$ as well as in the entire group of patients. Patients with depression and/or anxiety had statistically a higher risk of $\mathrm{CH}$ and $\mathrm{pMOH}$. In contrast, diagnostic and therapeutic management of headache was unrelated to the presence of depression and/or anxiety with only one single exception, i.e. an increased risk of contraindications against standard prophylactic medications in $\mathrm{EH}$.

These findings replicated in a clinic-based population well-known findings that patients with $\mathrm{CH}$ suffer from depression and/or anxiety more often than patients with $\mathrm{EH}[1,9,23-26]$, including suicidal attempts as shown in the literature [27]. Based on the concept of stagnation, Innamorati et al. [28, 29] showed that patients with medication overuse headache are burdened with a combination of psychological, behavioural and physical symptoms, and that in chronic migraine stagnation, characterized by feelings of obstruction of body, emotions and behaviour, is associated with depression. The impact of depression and anxiety on burden is much less known, however, and has been examined in three studies only [12-14]. A study in patients with chronic migraine and medication overuse found that depressive symptoms in these patients were associated with higher disability and lower quality of life [12]. Patients with posttraumatic stress disorder and migraine were more likely to be in the low poverty index and less likely to work for pay than patients with migraine alone, their work quality was cut 2.5-fold greater than in patients with 
Table 2 Gender, headache diagnoses and burden of headache in patients with EH and $\mathrm{CH}$ with and without depression and/or anxiety. HADS scores $\geq 8$ indicate presence of depression and/or anxiety, HADS scores $<8$ indicate absence of depression and/or anxiety

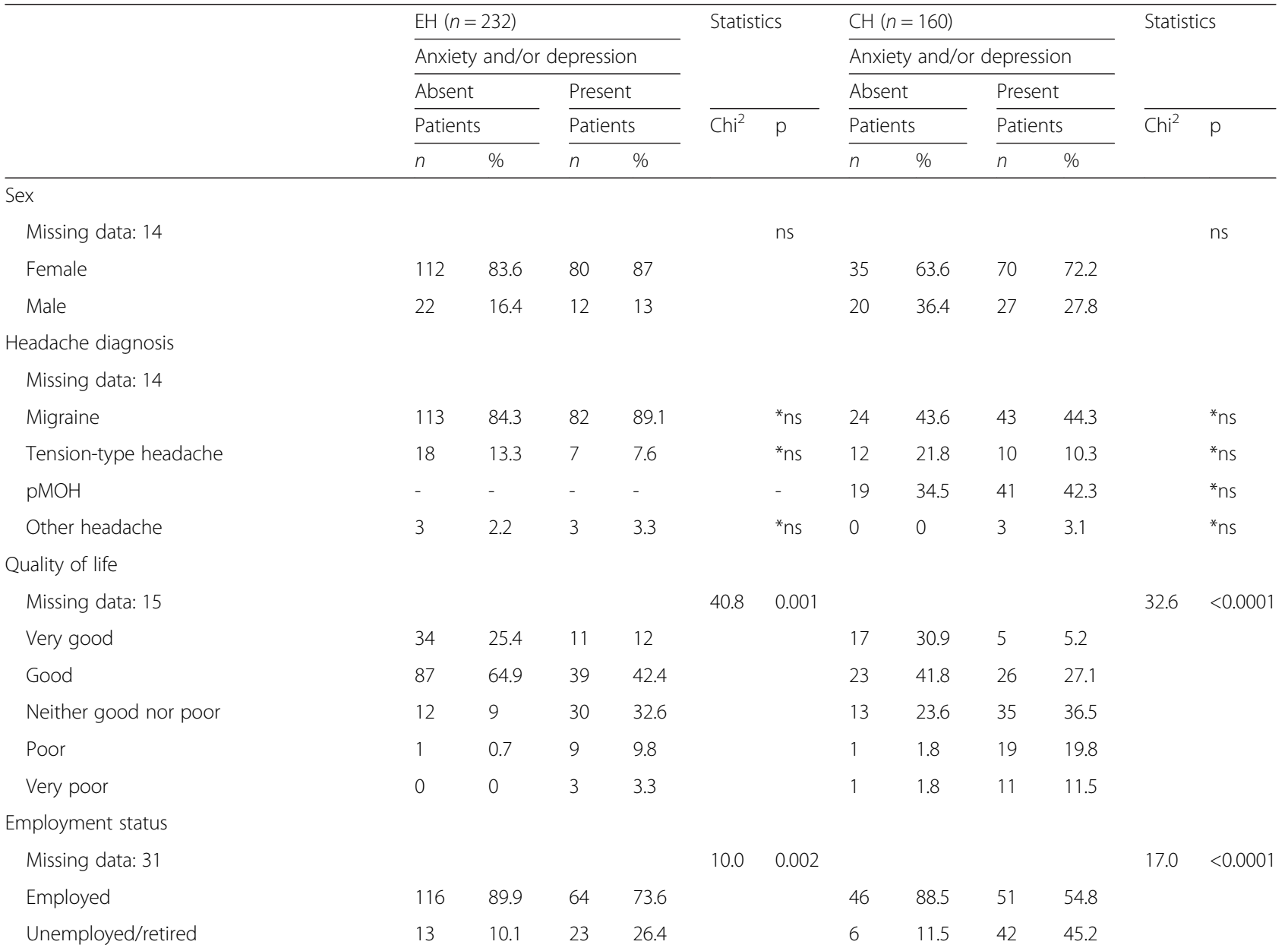
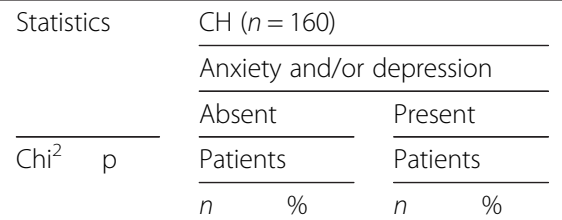

Statistics

Lost days in preceding 3 months**

Missing data: 56

ns

$0-5$

6-10

$\begin{array}{llll}41 & 32.3 . & 23 & 28.4\end{array}$

$\begin{array}{llll}13 & 26.5 & 10 & 12.7\end{array}$

$\begin{array}{llll}21 & 16.5 & 14 & 17.3\end{array}$

$11-20$

$>20$

$\begin{array}{llll}27 & 21.3 & 13 & 16\end{array}$

$\begin{array}{llll}38 & 29.9 & 31 & 38.3\end{array}$

Headache interfered with education

Missing data: 20

Yes

No

$\begin{array}{llll}38 & 29 & 36 & 39.6 \\ 93 & 71 & 55 & 60.4\end{array}$

ns

ns

Less successful in career due to HA

Missing data: 22

Yes

No

$\begin{array}{llll}34 & 25.8 & 38 & 43.2 \\ 98 & 74.2 & 50 & 56.8\end{array}$

$7.3 \quad 0.007$

ns

Reduced earnings due to HA

Missing data: 57

$9.1 \quad 0.003$ 
Table 2 Gender, headache diagnoses and burden of headache in patients with $\mathrm{EH}$ and $\mathrm{CH}$ with and without depression and/or anxiety. HADS scores $\geq 8$ indicate presence of depression and/or anxiety, HADS scores $<8$ indicate absence of depression and/or anxiety (Continued)

\begin{tabular}{|c|c|c|c|c|c|c|c|c|c|c|c|c|}
\hline \multicolumn{13}{|c|}{ HA understood by colleagues/employer } \\
\hline Missing data: 157 & & & & & 11.5 & 0.001 & & & & & 4.3 & 0.039 \\
\hline Yes & 73 & 78.5 & 29 & 51.8 & & & 24 & 70.6 & 25 & 48.1 & & \\
\hline No & 20 & 21.5 & 27 & 48.2 & & & 10 & 29.4 & 27 & 51.9 & & \\
\hline \multicolumn{13}{|c|}{ HA understood by family } \\
\hline Missing data: 25 & & & & & 8.8 & 0.003 & & & & & & ns \\
\hline Yes & 128 & 96.2 & 74 & 85.1 & & & 49 & 90.7 & 76 & 81.7 & & \\
\hline No & 5 & 3.8 & 13 & 14.9 & & & 5 & 9.3 & 17 & 18.3 & & \\
\hline \multicolumn{13}{|c|}{ Avoid telling people about HA } \\
\hline Missing data: 19 & & & & & 7.8 & 0.05 & & & & & 4.9 & 0.028 \\
\hline Yes & 33 & 24.8 & 38 & 42.7 & & & 19 & 34.5 & 51 & 53.1 & & \\
\hline No & 100 & 75.2 & 51 & 57.3 & & & 36 & 65.5 & 45 & 46.9 & & \\
\hline \multicolumn{13}{|c|}{ Feeling of being in control of the headaches } \\
\hline Missing data: 18 & & & & & & ns & & & & & & ns \\
\hline Yes & 91 & 67.9 & 58 & 65.2 & & & 34 & 63 & 52 & 53.6 & & \\
\hline No & 43 & 32.1 & 31 & 34.8 & & & 20 & 37 & 45 & 46.4 & & \\
\hline
\end{tabular}

${ }^{*}$ compared to all remaining diagnoses, ${ }^{* *}$ including lost workdays, lost housework days, workdays and housework days with productivity reduced to $<50 \%$, and lost days with leisure or family activities. ns not significant, na not applicable

migraine alone, and their difficulties getting along with social life were 2 -fold greater than in patients with migraine alone [13].

Recurrent or chronic headache and psychiatric comorbidities interact in a complex manner. Some longitudinal studies found clues for a bidirectional association: In adolescents anxiety and depression were associated with recurrent migraine (not tension-type headache) after four years [30], a higher migraine frequency was associated with higher depression and anxiety scores [31], depression and anxiety were significant risk factors for the chronification of migraine [12, 32, 33]. The risk of

Table 3 Odds ratios of having greater burden for presence versus absence of depression and/or anxiety

\begin{tabular}{|c|c|c|c|c|c|c|}
\hline & \multicolumn{2}{|c|}{ All patients $(n=392)$} & \multicolumn{2}{|c|}{$\mathrm{EH}(n=232)$} & \multicolumn{2}{|c|}{$\mathrm{CH}(n=160)$} \\
\hline & $\mathrm{OR}$ & $\mathrm{Cl}$ & OR & $\mathrm{Cl}$ & $\mathrm{OR}$ & $\mathrm{Cl}$ \\
\hline Being male & 1.1 & $0.67-1.80$ & 0.76 & $0.36-1.63$ & 0.68 & $0.33-1.37$ \\
\hline Having chronic headache & 2.57 & $1.68-3.93$ & na & na & na & na \\
\hline Having migraine & 1.35 & $0.87-2.10$ & 0.66 & $0.29-1.47$ & 1.03 & $0.53-2.00$ \\
\hline Having $\mathrm{pMOH}$ & 2.48 & $1.88-4.46$ & na & na & 1.39 & $0.70-2.76$ \\
\hline Having poor/very poor quality of life & 17.84 & $5.42-58.70$ & 19.95 & $2.55-156.33$ & 12.05 & $2.75-52-72$ \\
\hline Being unemployed/retired & 4.8 & $2.7-8.5$ & 3.21 & $1.52-6.76$ & 6.31 & $2.46-16.22$ \\
\hline Having $\geq 11$ lost days in preceding 3 months & 1.75 & $1.12-2.74$ & 1.13 & $0.65-1.98$ & 2.46 & $1.06-5.72$ \\
\hline HA interfered with education & 1.60 & $0.92-2.82$ & 1.60 & $0.91-2.82$ & 1.5 & $0.76-2.97$ \\
\hline Less successful in career due do HA & 2.19 & $1.43-3.37$ & 2.19 & $1.23-3.89$ & 1.77 & $0.90-3.51$ \\
\hline Reduced earning due to $\mathrm{HA}$ & 3.16 & $1.78-5.59$ & 3.28 & $1.47-7.29$ & 2.16 & $0.93-5.10$ \\
\hline HA not understood by colleagues/employer & $3.23-$ & $1.85-5.64$ & 3.40 & $1.65-6.99$ & 2.59 & $1.04-6.48$ \\
\hline HA not understood by family & 3.54 & $1.68-7.48$ & 4.50 & $1.54-13.12$ & 2.19 & $0.76-6.33$ \\
\hline Avoid telling people about HA & 2.43 & $1.58-3.73$ & 2.26 & $1.27-4.02$ & 2.15 & $1.08-4.26$ \\
\hline Feeling of being in control of the headaches & 0.73 & $0.48-1.11$ & 0.88 & $0.50-1.56$ & 0.68 & $0.34-1.34$ \\
\hline
\end{tabular}

OR odds ratio, $\mathrm{Cl} 95 \%$ confidence interval, na not applicable 
Table 4 Summarized data for five classes of standard prophylactic medications (betablocker, flunarizine, valproate, topiramate, amitriptyline) in patients with $\mathrm{EH}$ and $\mathrm{CH}$ with and without depression and/or anxiety, differentiating "none" or "one and more prophylactics". HADS scores $\geq 8$ indicate presence of depression and/or anxiety, HADS scores $<8$ indicate absence of depression and/or anxiety

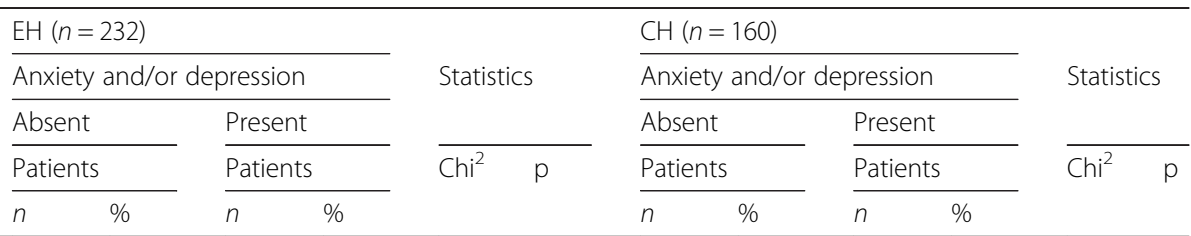

Ever-before use

Missing data: 27

None

$\begin{array}{llll}59 & 45.7 & 40 & 44.9\end{array}$

One ore more prophylactics

$\begin{array}{llll}70 & 54.3 & 49 & 55.1\end{array}$

\section{9}

Contraindications

Missing data: 43

None

One or more

$\begin{array}{llll}96 & 76.8 & 54 & 63.5 \\ 29 & 23.2 & 31 & 36.5\end{array}$

Adverse effects

Missing data: 25

None

Caused by one or more prophylactics

$\begin{array}{llll}43 & 68.3 & 30 & 69.8\end{array}$

Use for $\geq 3$ months

Missing data: 19

None

One or more prophylactics

$\begin{array}{llll}17 & 26.6 & 7 & 14.9 \\ 47 & 73.4 & 40 & 85.1\end{array}$

Intake of an adequate dose

Missing data: 23

None

One or more prophylactics

$\begin{array}{llll}5 & 7.9 & 6 & 13.6 \\ 58 & 92.1 & 38 & 86.4\end{array}$

Decrease in HA frequency by $\geq 50 \%$

Missing data: 33

\begin{tabular}{lllll} 
None & 28 & 50.9 & 25 & 58.1 \\
Caused by one or more prophylactics & 27 & 49.1 & 18 & 41.9 \\
\hline
\end{tabular}

$4.4 \quad 0.037$

$\begin{array}{llll}27 & 50 & 39 & 41.9 \\ 27 & 50 & 54 & 58.1\end{array}$

$\begin{array}{llll}41 & 77.4 & 68 & 79.1 \\ 12 & 22.6 & 18 & 20.9\end{array}$

ns

$\begin{array}{llll}21 & 87.5 & 34 & 66.7 \\ 3 & 12.5 & 17 & 33.3\end{array}$

ns

$\begin{array}{llll}5 & 19.2 & 9 & 18 \\ 21 & 80.8 & 41 & 82\end{array}$

ns

ns not significant

having a major depression in patients with migraine was as high as the risk for getting migraine in patients with major depression, and the risk for major depression was higher in persons with migraine compared to persons without migraine [33]. A recent study found an increased migraine frequency in patients with anxiety or depression [14]. Our study was a cross-sectional study, therefore odds ratios have to be interpreted cautiously.

Our data showed that the impact of depression and anxiety on daily activities is high in patients with $\mathrm{CH}$. Over $80 \%$ of the patients with $\mathrm{CH}$ and depression and/ or anxiety lost more than ten days of productivity, family, social and leisure activities during the previous three months. This may increase their risk of losing the job, thus contributing to the lower socioeconomic status of patients with chronic pain [5]. In contrast, the numbers of lost days were comparable in the other study groups, i.e. EH without and with depression and/or anxiety and $\mathrm{CH}$ without depression and/or anxiety. Markedly more patients in our study reported that their headaches interfered with education, careers and earnings than in the study of Steiner et al. [10], and these reports were even higher in patients with depression and/or anxiety, although not statistically significant. There is a substantial impact on education, career and earnings in the patients' perception. Lower education levels and lower socioeconomic status were associated with an increased risk of getting migraine [34], and patients with chronic migraine were less likely to be working for pay than patients with episodic migraine [35]. So far, the impact of 
$\mathrm{EH}, \mathrm{CH}$ and depression and/or anxiety on the employment status has not been studied.

Furthermore, social support was affected by the presence of anxiety and/or depression resulting in increased risks of feeling less understood by the family, employer and colleagues as well as an increased risk of avoiding to tell other people about the headache. This was true for the entire group of patients as well as for those with $\mathrm{EH}$ and $\mathrm{CH}$, with one exception. The difference for the family's understanding on ones headaches did not reach the level of statistical significance in $\mathrm{CH}$. In contrast, D'Amico et al. [36] found only little evidence for the impact of perceived social support on chronic migraine.

In accordance with other studies [25, 37] patients with $\mathrm{CH}$ consulted general practitioners more often. In the present subgroup analysis we did not find differences in health care use and technical examinations between patients with and without depression and/or anxiety. But the numbers of patients in each group were relatively small, so we cannot draw a definite conclusion with regards to the influence of depression and anxiety. A recent study [38] found in-hospital stays six times, outpatient visits four times and emergency department visits three times as much in migraine patients with compared to those without psychiatric comorbidities. In addition the patients with psychiatric comorbidities underwent computer tomography and magnetic resonance imaging of the brain more often.

As in the main study the ever-before use of prophylactic medication was low, but in contrast to the main study the ever-before use did not differ between patients with $\mathrm{EH}$ and $\mathrm{CH}$ [11]. This may be attributed to the smaller patient number in the present analysis. Moreover the overall low use of prophylactic drugs may be caused by patient or physician related factors: patients may deny taking prophylactic drugs, neurologists may try non-drug prophylaxis first, or especially physicians who are not specialized in headache treatment may not think of prophylactic drugs. We did not ask the treating neurologists and patients for the reasons of not prescribing or taking prophylactics, and we are not aware of other studies dealing with this issue. Interestingly, betablocker and flunarizine, although having the potential of triggering or worsening depression, had ever been used by a substantial number of patients with depression and/ or anxiety. The neurologists assessed possible contraindications based on the patient's history and on their own discretion. For clarity and comparability for each drug the main contraindications according to the prescribing information were listed in the questionnaire. The prescription pattern in this study also reflects the treatment of headache patients in neurological offices, as we included patients who came for a first-time visit to one of the headache centres as well as patients who came for a control visit. Our findings emphasize that the choice of prophylactic drugs needs to be improved, especially with regards to depression and anxiety. Adverse effects, duration of prophylactic treatment, intake of an adequate dose and decrease in headache frequency by $\geq 50 \%$ did not differ between patients with and without anxiety and/or depression, but patient numbers in the groups were too small do draw definite conclusions. Given the impact of depression and anxiety on recurrent and chronic headache further studies on therapeutic impact are urgently needed. To the best of our knowledge no previous study addressed this topic up till now.

Limitations of this study are the post-hoc analysis and relatively small patient numbers in the subgroups of some items. As this was an exploratory analysis, we did not correct for multiple testing. We did not analyse the dataset differentiated by migraine, tension-type headache, $\mathrm{pMOH}$ and other headaches or differentiated by anxiety alone, depression alone or anxiety and depression, because the subgroups would have been too small. The HADS is a validated and widely used questionnaire for screening for depression and anxiety, but it does not allow a clinical diagnosis of depression or anxiety, and patients in this study did not undergo a psychiatric interview. Finally, we must bear in mind that comorbidity rates in clinic-based studies may be higher than in population-based studies because of an increased vigilance or selection bias.

Strengths of the study are the large clinic-based sample from eight headache centres with high participation rates, and the use of validated questionnaires for establishing headache diagnoses and for assessing depression and anxiety.

\section{Conclusion}

This is one of the first studies looking at the impact of depression and anxiety on $\mathrm{EH}$ and $\mathrm{CH}$ in a clinic-based patient sample. Patients with $\mathrm{CH}$ suffer from depression and/ or anxiety significantly more often than patients with $\mathrm{EH}$. More importantly, the quality of life is deceased and the burden is further increased by depression and/or anxiety in patients with $\mathrm{EH}$ and $\mathrm{CH}$. In addition, treatment with prophylactic medications is sub-optimal in patients with depression and/or anxiety. In particular for these patients a comprehensive treatment approach including pharmacological and non-pharmacological treatments (such as behavioural therapy, relaxation training, coping strategies) is necessary in order to decrease disability on the personal, social and occupational level.

\footnotetext{
Competing interests

KZ received honoraria and travel funding from Allergan and Menarini, AL received honoraria from Allergan, GB received honoraria and travel funding from Allergan, Menarini, Pfizer and Astra Zeneca, CL serves on scientific advisory boards for Allergan and received funding for travel from Bayer Schering Pharma, Merck Serono, and Teva Pharmaceutical Industries Ltd. serves as a consultant to Allergan and Bayer Schering Pharma; receives
} 
research support from Allergan and Bayer Schering Pharma; received personal compensation for consultations or lectures from Bayer HealthCare, Sanofi Aventis, Biogen Idec, Teva Pharmaceuticals.

GL received honoraria from Allergan, AW declares he has no competing interests, SMO declares she has no competing interests, KB received honoraria from Allergan and Biogen Idec Research Limited and travel funding from Daiichi Sankyo Austria GmbH, CW received honoraria from Allergan and Pfizer, is consultant to Curelator.

\section{Authors' contributions}

KZ conceived the study, contributed to data acquisition and statistical analysis and drafted the manuscript. AL contributed to the design of the study and contributed to data acquisition. GB conceived the study and contributed to data acquisition. CL participated in the study design and contributed to data acquisition. GL, AW, SO and KB contributed to the design of the study and data acquisition. CW conceived the study, contributed to data acquisition and drafting of the manuscript and revised the manuscript critically. All authors read and approved the final manuscript.

\section{Acknowledgment}

We thank Colette Andree for analysing the data of the Eurolight questionnaire with the Eurolight algorithm and Michaela Schmöger and Ulrike Willinger for statistical advice.

This study was partly funded by an unrestricted scientific grant from Allergan. However, Allergan was not involved in study design, collection, analysis and interpretation of data, writing of the manuscript and in the decision to submit the manuscript for publication.

\section{Author details}

${ }^{1}$ Department of Neurology, Medical University of Vienna, Währinger Gürtel 18-20, 1090 Vienna, Austria. ${ }^{2}$ Department of Neurology, Medical University of Graz, Graz, Austria. ${ }^{3}$ Department of Neurology, Medical University of Innsbruck, Innsbruck, Austria. ${ }^{4}$ Headache Centre Seilerstätte, Hospital Sisters of Charity Linz, Linz, Austria. ${ }^{5}$ University Clinic of Neurology, Christian-Doppler-Klinik Salzburg, Salzburg, Austria. ${ }^{6}$ Neurological Office Vienna, Vienna, Austria. 'Department of Neurology, Klinikum Klagenfurt, Klagenfurt, Austria. ${ }^{8}$ Department of Neurology, aö. BKH Kufstein, Kufstein, Austria.

Received: 19 November 2015 Accepted: 10 February 2016 Published online: 27 February 2016

\section{References}

1. Stovner LJ, Andree C (2010) Prevalence of headache in Europe: a review for the Eurolight project. J Headache Pain 11:289-299

2. Vos T, Flaxman AD, Naghavi M et al (2012) Years lived with disability (YLDs) for 1160 sequelae of 289 diseases and injuries 1990-2010: a systematic analysis for the Global Burden of Disease Study. Lancet 380:2163-2196

3. Stovner LJ, Zwart JA, Hagen K, Terwindt G, Pascual J (2006) Epidemiology of headache in Europe. Eur J Neurol 13:333-345

4. Katsarava Z, Obermann M (2013) Medication-overuse headache. Curr Opin Neurol 26:276-281

5. Buse DC, Manack A, Serrano D, Turkel C, Lipton RB (2010) Sociodemographic and comorbidity profiles of chronic migraine and episodic migraine sufferers. J Neurol Psychiatry 81:428-432

6. Buse DC, Silberstein SD, Manack AN, Papapetropoulos S, Lipton RB (2013) Psychiatric comorbidities of episodic and chronic migraine. J Neurol 260: 1960-1969

7. Radat F, Swendsen J (2004) Psychiatric comorbidity in migraine: a review. Cephalalgia 25:165-178

8. Stovner LJ, Andree C (2008) Impact of headache in Europe: a review for the Eurolight project. J Headache Pain 9:139-146

9. Adams AM, Serrano D, Buse DC, Reed ML, Marske V, Fanning KM, Lipton RB (2015) The impact of chronic migraine: the chronic migraine epidemiology and outcomes (CaMEO) study. Cephalalgia 35(7):563-578

10. Steiner TJ, Stovner LJ, Katsarava Z, Lainez JM, Lampl C, Lanteri-Minet M, Rastenyte D, Ruiz de la Torre E, Tassorelli C, Barre J, Andree C (2014) The impact of headache in Europe: principal results of the Eurolight project. $J$ Headache Pain 15:31-41

11. Zebenholzer K, Andree C, Lechner A, Broessner G, Lampl C, Luthringshausen G, Wuschitz A, Obmann SM, Berek K, Wöber C (2015) Prevalence, management and burden of episodic and chronic headache a cross-sectional multicentre study in eight Austrian headache centres. J Headache Pain 16:46

12. Bigal M (2009) Migraine chronification - concept and risk factors. Discov Med 8:145-150

13. Rao AS, Scher Al, Vieira RV, Merikangas KR, Metti AL, Peterlin BL (2015) The impact of post-traumatic stress disorder on the burden of migraine: results from the national comorbidity survey-replication. Headache. doi:10.1111/ head.12698

14. Oh K, Cho SJ, Kim JM, Chu MK (2014) Combination of anxiety and depression is associated with an increased headache frequency in migraineurs: a population-based study. BMC Neurol 14:238

15. Andree C, Vaillant M, Barre J, Katsarava Z, Lainez JM, Lair ML, Lanteri-Minet M, Lampl C, Steiner TJ, Stovner LJ, Tassorelli C, Sandor PS (2010) Development and validation of the Eurolight questionnaire to evaluate the burden of primary headache disorders in Europe. Cephalalgia 30:1082-1100

16. Headache Classification Subcommittee of the International Headache Society (2014) The International Classification of Headache Disorders: 2nd edition. Cephalalgia 24(Suppl):1-160

17. Steiner TJ (2007) The HALT and HART indices. J Headache Pain 8:S22-S25

18. The WHOQOL Group (1998) Development of the World Health Organization WHOQOL-BREF quality of life assessment. Psychol Med 28:551-558

19. Herrmann-Lingen C, Buss U, Snaith RP (2011) Hospital Anxiety and Depression Scale - Deutsche Version (HADS-D) Verlag Hans Huber, Bern

20. Luthringshausen G, Alesch F, Brössner G, Sator-Katzenschlager S, Vesper J, Wessely P, Wöber C (2014) Chronische Migräne: Therapie, Therapieresistenz und Neuromodulation - Ein Konsensus Statement. J Neurol Neurochir Psychiatr 15:163-168

21. Evers S, Áfra J, Frese A, Goadsby PJ, Linde M, May A, Sándor P (2009) EFNS guidelines on the drug treatment of migraine - revised report of an EFNS task force. Eur J Neurol 16:968-991

22. Steiner TJ, Gururaj G, Andree C, Katsarava Z, Ayzenberg I, Yu SY, Al Jumah M, Tekle-Haimanot R, Birbeck GL, Herekar A, Linde M, Mbewe E, Manandhar K, Risal A, Jensen R, Queiroz LP, Scher Al, Wang SJ, Stovner LJ (2014) Diagnosis, prevalence estimation and burden measurement in population surveys of headache: presenting the HARDSHIP questionnaire. J Headache Pain 15:3

23. Kristofferson ES, Grande RB, Aaseth K, Lundquist C, Russel MB (2012) Management of primary chronic headache in the general population: the Akershus study of chronic headache. J Headache Pain 13:113-120

24. Bigal ME, Lipton RB (2008) Excessive acute migraine medication use and migraine progression. Neurology 71:1821-1828

25. Blumenfeld A, Varon S, Wilcox TK, Buse D, Kawata AK, Manack A, Goadsby PJ, Lipton RB (2011) Disability, HRQoL and resource use among chronic and episodic migraineurs: results from the International Burden of Migraine Study (IMBS). Cephalalgia 31:301-315

26. Buse DC, Manack AN, Serrano D, Varon SF, Turkel, Lipton RB (2012) Headache impact of chronic and episodic migraine: predictors of impact from the American Migraine Prevalence and Prevention (AMPP) study. Headache 52(1):3-17

27. Pompili M, Serafini G, Di Cosimo D, Dominici G, Innamorati M, Lester D, Forte A, Girardi N, De Filippis S, Tatarelli R, Martelletti P (2010) Psychiatric comorbidity and suicide risk in patients with chronic migraine. Neuropsychiatr Dis Treat 6:81-91

28. Innamorati M, Pompili M, Erbuto D, Ricci F, Migliorati M, Lamis DA, Amore M, Girardi P, Martelletti P (2015) Psychometric properties of the stagnation scale in medication overuse headache patients. J Headache Pain 16:2

29. Innamorati M, Pompili M, Fiorillo M, Lala N, Negro A, Diletta del Bono S, Lester D, Girardi P, Martelletti P (2013) Overattachment and perceived disability in chronic migraineurs. Clin Neurol Neurosurg 115:954-958

30. Blaauw BA, Dyb G, Hagen K, Holmen TL, Linde M, Wentzel-Larsen T, Zwart JA (2015) The relationship of anxiety, depression and behavioral problems with recurrent headache in late adolescence - a Young-HUNT follow-up study. J Headache Pain 16:10

31. Goulart AC, Santos IS, Brunoni AR, Nunes MA, Passos VM, Griep RH, Lotufo PA, Bensenor IM (2014) Migraine headaches and mood/anxiety disorders in the ELSA Brazil. Headache 54(8):1310-1319

32. Kroenke K, Spitzer RL, Williams JB, Lowe B (2010) The patient health questionnaire somatic, anxiety, and depressive symptoms scales: a systematic review. Gen Hosp Psychiatry 32:345-359

33. Ashina S, Buse DC, Maizels M, Manack A, Serrano D, Turkel CC, Lipton RB (2010) Self-reported anxiety as a risk factor for migraine chronification: 
results from the American Migraine Prevalence and Prevention (AMPP) study. Headache 50(Suppl 1):4

34. Le H, Tfelt-Hansen P, Skytthe A, Kyvik KO, Olesen J (2011) Association between migraine, lifestyle and socioeconomic factors: a population-based cross-sectional study. J Headache Pain 12(2):157-172

35. Stewart WF, Wood GC, Manack A, Varon SF, Buse DC, Lipton RB (2010) Employment and work impact of chronic migraine and episodic migraine. J Occup Environ Med 52(1):8-14

36. D'Amico D, Grazzi L, Bussone G, Curone M, Di Fiore P, Usai S, Leonardi M Giovannetti AM, Schiavolin S, Raggi A (2015) Are depressive symptomatology, self-efficacy, and perceived social support related to disability and quality of life in patients with chronic migraine associated to medication overuse? Data from a cross-sectional study. Headache 55:636-645

37. Breslau N, Davis GC, Schultz LR, Peterson EL (1994) Migraine and major depression: a longitudinal study. Headache 34:387-393

38. Minen MT, Tanev K (2014) Influence of psychiatric comorbidities in migraineurs in the emergency department. Gen Hops Psychiatry 36(5):533-538

\section{Submit your manuscript to a SpringerOpen ${ }^{\odot}$ journal and benefit from:}

- Convenient online submission

- Rigorous peer review

- Immediate publication on acceptance

- Open access: articles freely available online

- High visibility within the field

- Retaining the copyright to your article 